\title{
Distinct Patterns of Blood Cytokines Beyond a Cytokine Storm Predict Mortality in COVID-19
}

Christian Herr, (ID) Sebastian Mang,' Bahareh Mozafari,' Katharina Guenther,' Thimoteus Speer, ${ }^{2}$ Martina Seibert,' Sanjay Kumar Srikakulam,' Christoph Beisswenger,' Felix Ritzmann, ' Andreas Keller, ${ }^{3}$ Rolf Mueller, ${ }^{4}$ Sigrun Smola, ${ }^{5}$ Dominic Eisinger, (D ${ }^{6}$ Michael Zemlin, ${ }^{7}$ Guy Danziger, ${ }^{1}$ Thomas Volk, ${ }^{8}$ Sabrina Hoersch, ${ }^{8}$ Marcin Krawczyk, ${ }^{9}$ Frank Lammert, (iD) ${ }^{9}$ Thomas Adams, (iD) ${ }^{9}$ Gudrun Wagenpfeil, ${ }^{10}$ Michael Kindermann," "Constantin Marcu," Zuhair Wolf Dietrich Ataya, ${ }^{12}$ Marc Mittag, ${ }^{13}$ Konrad Schwarzkopf, ${ }^{13}$ Florian Custodis, ${ }^{13}$ Daniel Grandt, ${ }^{13}$ Harald Schaefer, ${ }^{14}$ Kai Eltges, ${ }^{14}$ Philipp M Lepper,' Robert Bals'

On behalf of the CORSAAR Study Group

'Department of Internal Medicine V Pulmonology, Allergology and Critical Care Medicine, Saarland University, Homburg, 6642I, Germany; ${ }^{2}$ Department of Internal Medicine IV - Nephrology and Hypertension \& Translational Cardio-Renal Medicine, Saarland University, Homburg, 6642I, Germany;

${ }^{3}$ Clinical Bioinformatics, Saarland University, Homburg, 6642I, Germany; ${ }^{4}$ HelmholtzInstitute for Pharmaceutical Science Saarland Saarbrücken, 66I23, Germany; ${ }^{5}$ Institute for Virology, Saarland University, Homburg, 6642I, Germany; ' $M y r i a d$ RBM Inc., Austin, TX, 78759,

USA; ${ }^{7}$ Department of General Pediatrics and Neonatology, Saarland University, Homburg, 6642I, Germany: ${ }^{8}$ Department of

Anesthesiology, Intensive Care Medicine and Pain Therapy, Saarland University, Homburg, 6642I, Germany; ' ${ }^{9}$ epartment of Internal Medicine II - Gastroenterology, Saarland University, Homburg, 6642I, Germany;

${ }^{10}$ Institute for Medical Biometry, Epidemiology and Medical Informatics, Saarland University, Homburg, 6642I, Germany; "Department of Internal Medicine, Cardiology and Intensive Care Medicine, Caritas Hospital St. Theresia Saarbrücken, Saarbrücken, 66II3, Germany;

${ }^{12}$ Department of Gastroenterology, Internal and Intensive Care Medicine, Caritas Hospital St. Josef Saarbrücken, Saarbrücken, 66I25,

Germany; ${ }^{13}$ Department of Anesthesiology,

Gastroenterology and Intensive Care Medicine,
Background: COVID-19 comprises several severity stages ranging from oligosymptomatic disease to multi-organ failure and fatal outcomes. The mechanisms why COVID-19 is a mild disease in some patients and progresses to a severe multi-organ and often fatal disease with respiratory failure are not known. Biomarkers that predict the course of disease are urgently needed. The aim of this study was to evaluate a large spectrum of established laboratory measurements.

Patients and Methods: Patients from the prospective PULMPOHOM and CORSAAR studies were recruited and comprised 35 patients with COVID-19, 23 with conventional pneumonia, and 28 control patients undergoing elective non-pulmonary surgery. Venous blood was used to measure the serum concentrations of 79 proteins by Luminex multiplex immunoassay technology. Distribution of biomarkers between groups and association with disease severity and outcomes were analyzed.

Results: The biomarker profiles between the three groups differed significantly with elevation of specific proteins specific for the respective conditions. Several biomarkers correlated significantly with disease severity and death. Uniform manifold approximation and projection (UMAP) analysis revealed a significant separation of the three disease groups and separated between survivors and deceased patients. Different models were developed to predict mortality based on the baseline measurements of several protein markers. A score combining IL-1ra, IL-8, IL-10, MCP-1, SCF and CA-9 was associated with significantly higher mortality (AUC 0.929).

Discussion: Several newly identified blood markers were significantly increased in patients with severe COVID-19 (AAT, EN-RAGE, myoglobin, SAP, TIMP-1, vWF, decorin) or in patients that died (IL-1ra, IL-8, IL-10, MCP-1, SCF, CA-9). The use of established assay technologies allows for rapid translation into clinical practice.

Keywords: biomarker, inflammation, SARS-CoV2

\section{Introduction}

Coronavirus disease 2019 (COVID-19) is a novel illness and a rapidly evolving pandemic with large impact on global health. COVID-19 is caused by "severe acute respiratory syndrome coronavirus 2" (SARS-CoV-2), a member of the Coronaviridae family that is regarded as a spill-over of an animal coronavirus to humans. ${ }^{1}$ At the time of submission of this work, SARS-CoV-2 has caused 120 million diagnosed infections and 6 million known deaths. The disease course is complex, increasing disease severity is associated with respiratory and extra-pulmonary organ manifestations. Most of the infected individuals have mild flu-like symptoms, nevertheless, about $20 \%$ of individuals develop more severe illness due to viral pneumonia, often resulting in the need for hospitalization. Often, the disease progresses, and patients need 


\section{Graphical Abstract}

\section{Prognostic biomarkers in COVID-19}

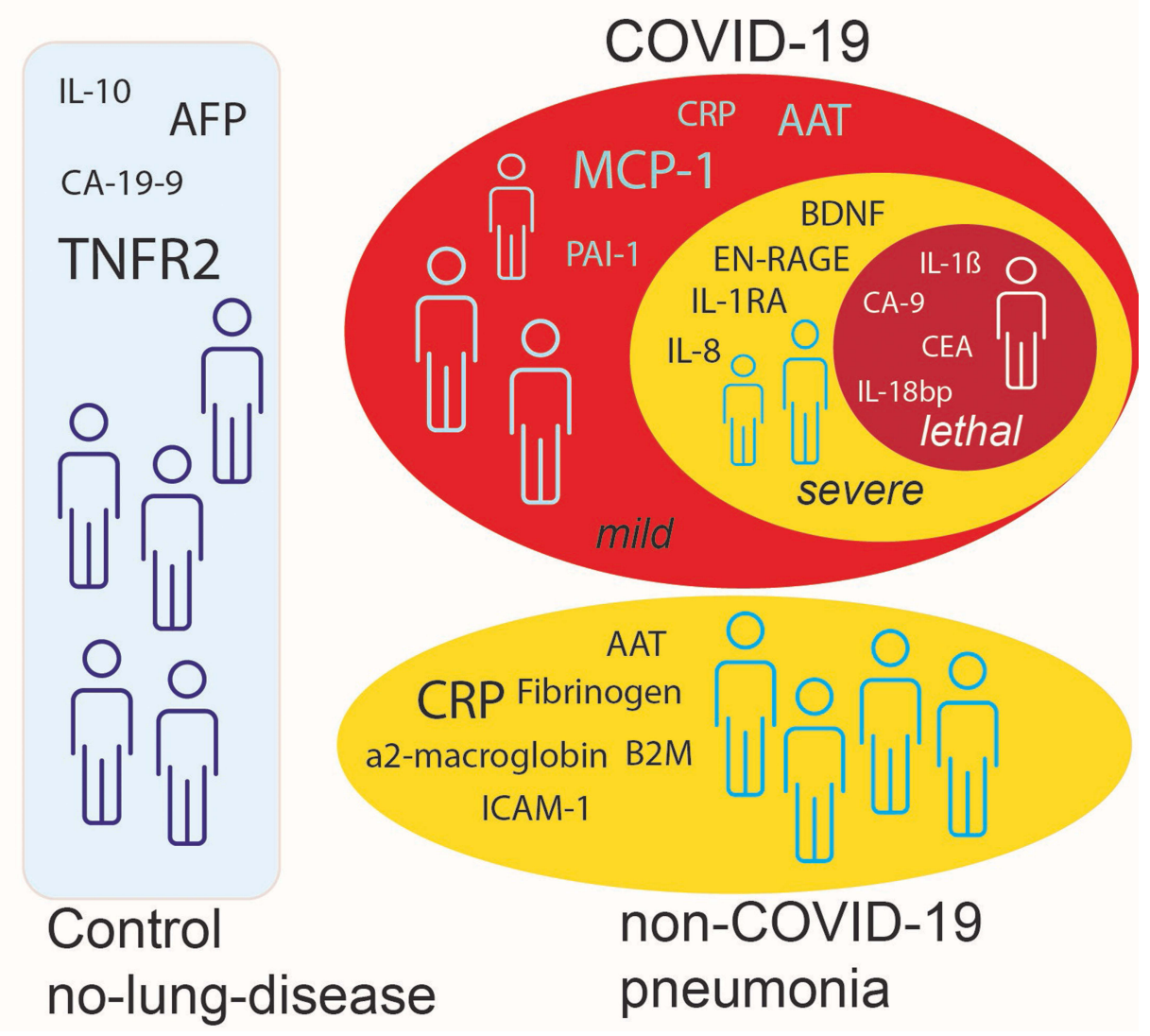

Saarbrücken Hospital, Saarbrücken, 66119, Germany; ${ }^{14}$ Department of Internal Medicine and Pulmonology, SHG-Hospital Völklingen, Saarbrücken, 66333, Germany
Correspondence: Robert Bals Department of Internal Medicine V Pulmonology, Allergology and Critical Care Medicine, Saarland University, Homburg, 6642I, Germany Tel +49684I 16 I505I

Email robert.bals@uks.eu invasive life support. The mechanisms why COVID-19 is a mild disease in some patients and progresses to a severe multi-organ and often fatal disease with respiratory failure are currently unknown.

The natural history and the pathomechanisms of COVID-19 involve complex mechanisms including infection and viral replication in target cells and a broad dysregulation of host defense, immune mechanisms, and coagulation. Several studies have evaluated blood transcriptional data and highlighted the importance of dysregulation of innate ${ }^{2}$ or adaptive immunity including activation of type 1 (t-bet, interferon- $\gamma$ ), type-2 (GATA) or type 3 (ROR $\gamma$ t, IL-17) immune pathways.,

Elevation of routine inflammation markers, such as erythrocyte sedimentation rate, C-reactive protein (CRP) or procalcitonin (PCT), is frequently but not exclusively observed in the critically ill COVID-19 patient. ${ }^{5}$ The term "cytokine storm" has been used to describe the elevation of several acute-phase proteins such as CRP, interleukin-6 (IL-6) or ferritin. ${ }^{6,7}$ Individual markers like IL-6, IL-8 or patterns from multi-omics analysis have been associated with disease severity and lethality. ${ }^{8-12}$ 
Pathological findings implicated that the plasminogenplasmin system is involved in the progression of the disease. ${ }^{13,14}$ Diffuse alveolar lesions, microthrombi and frequent hemorrhage in the alveolar region were observed in autopsied patients. The concentration of tissue type plasminogen activator (tPA) and plasminogen activation inhibitor-1 (PAI-1) correlated with the lung damage. High levels of tPA enhanced fibrinolysis and were strongly correlated with mortality. ${ }^{15}$ In contrast, in a different cohort a decrease of fibrinolysis was shown in severely infected patients. ${ }^{16}$ In another study, the authors showed a strong correlation of plasminogen concentrations with mortality in COVID-19 patients. $^{17}$

There is a clinical need to identify markers that indicate the risk of disease progression or fatal outcome. The aim of the present study was to identify clinically relevant serum biomarkers from a large spectrum of established laboratory measurements. The marker panel applied in the present study consists of mediators of inflammation and immunity, which are not yet part of clinical routine testing but have been shown to be involved in cellular or humoral immune responses. We measured serum levels of a large panel of cytokines, chemokines, acute phase reactants, growth factors, tissue remodeling enzymes and clinical laboratory parameters in blood samples of hospitalized COVID-19 patients and compared them to control individuals undergoing non-thoracic surgery as well as patients with community-acquired pneumonia.

\section{Methods}

\section{Study Population}

The present analysis used the baseline data and follow up data of the COVID-19 cohort CORSAAR $(n=35)$ and its control cohort PULMOHOM, which are multi-center studies focusing on pathomechanisms and the role of risk factors in COVID-19 and other inflammatory lung diseases. Within the PULMOHOM cohort study, 23 patients with pneumonia and 28 control patients undergoing elective non-pulmonary surgery have been included. The inclusion criteria for this non-pulmonary, surgical cohort were: Planned surgery, no known pulmonary disease, male sex, and central venous line placement during surgery. The presence of a central venous line allowed sampling from the same site as in the critically ill COVID-19 and ARDS-patients. Patients for the COVID-19 cohort were included within 3 days of admittance to the hospital and recruited at the Saarland University Hospital Homburg, the Caritas Hospital
Saarbrücken (St. Theresia and St. Josef), the Hospital Saarbrücken (Winterberg), and the SHG-Hospital Völklingen. The studies have been approved by the ethics committee of the Medical Council of the Saarland (“Ärztekammer des Saarlandes"), and all patients or their legal representatives gave their informed consent. Basic and anthropomorphic characteristics, the prevalence of comorbidities, and vital parameters were assessed based on measurements, questionnaires, and standardized interviews.

\section{Biosamples}

Blood samples were drawn within 6 hours after obtaining informed consent from the patient and processed within 4 hours (time-to-centrifugation). Blood was centrifuged for 20 minutes at $2500 \mathrm{~g}$ at $4^{\circ} \mathrm{C}$ in a swing out rotor with break. The serum supernatant was separated immediately after centrifugation under aseptical conditions and transferred into cryo-vials. The vials were integrated into our local biobank $\left(-80^{\circ} \mathrm{C}\right.$ storage and Biobank Information System (BIMS)) for long-term storage. The freezers of the biobank are temperature monitored and access controlled. Upon selection for analysis, the samples were sent on dry ice to the corresponding labs.

\section{Multiplex Immunoassay Analysis}

All samples were stored at less than $-70^{\circ} \mathrm{C}$ until tested. Samples were thawed at room temperature, vortexed, spun at $3700 \mathrm{~g}$ for $5 \mathrm{~min}$ for clarification and transferred to a master microtiter plate. Using automated pipetting, an aliquot of each sample was added to individual microsphere multiplexes of the selected Multi Analyte Profile (MAP) and blocker. This mixture was thoroughly mixed and incubated at room temperature for 1 hour. Multiplexed cocktails of biotinylated reporter antibodies were added robotically and after thorough mixing, incubated for an additional hour at room temperature. Multiplexes were labelled using an excess of streptavidin-phycoerythrin solution, thoroughly mixed and incubated for 1 hour at room temperature. The volume of each multiplexed reaction was reduced by vacuum filtration and washed thrice. After the final wash, the volume was increased by addition of buffer for analysis using a Luminex instrument and the resulting data interpreted using proprietary software developed by Myriad RBM. For each multiplex, both calibrators and controls were included on each microtiter plate. Eightpoint calibrators to form a standard curve were run in the first and last column of each plate and controls at three 
concentration levels were run in duplicate. Standard curve, control, and sample QC were performed to ensure proper assay performance. Study sample values for each of the analytes were determined using 4 and 5 parameter logistics, weighted and non-weighted curve fitting algorithms included in the data analysis package.

The following assays were used: adiponectin, alpha1-antitrypsin (AAT), alpha-2-macroglobulin (A2Macro), apolipoprotein(a) (Lp(a)), beta-2-microglobulin (B2M), brain-derived neurotrophic factor (BDNF), c-reactive protein (CRP), complement C3 (C3), EN-RAGE, eotaxin-1, factor VII, ferritin (FRTN), fibrinogen, granulocyte-macrophage colony-stimulating factor (GM-CSF), haptoglobin, immunoglobulin a (IgA), immunoglobulin $\mathrm{m}$ (IgM), intercellular adhesion molecule 1 (ICAM-1), interferon gamma (IFNgamma), interleukin-1 alpha (IL-1 alpha), interleukin-1 beta (IL-1 beta), interleukin-1 receptor antagonist (IL-1 ra), interleukin-2 (IL-2), interleukin-3 (IL-3), interleukin-4 (IL-4), interleukin-5 (IL-5), interleukin-6 (IL-6), interleukin-7 (IL7), interleukin-8 (IL-8), interleukin-10 (IL-10), interleukin12 Subunit p40 (IL-12p40), interleukin-12 subunit p70 (IL12p70), interleukin-17 (IL-17), interleukin-18 (IL-18), macrophage inflammatory protein-1 alpha (MIP-1 alpha), macrophage inflammatory protein-1 beta (MIP-1 beta), matrix metalloproteinase-3 (MMP-3), matrix metalloproteinase-9 (MMP-9), monocyte chemotactic protein 1 (MCP-1), myoglobin, plasminogen activator inhibitor 1 (PAI-1), pulmonary and activation-regulated chemokine (PARC), serum amyloid p-component (SAP), stem cell factor (SCF), t-cellspecific protein RANTES (RANTES), thyroxine-binding globulin (TBG), tissue inhibitor of metalloproteinases 1 (TIMP-1), tumor necrosis factor alpha (TNF-alpha), tumor necrosis factor beta (TNF-beta), tumor necrosis factor receptor 2 (TNFR2), vascular cell adhesion molecule-1 (VCAM1), vascular endothelial growth factor (VEGF), vitamin d-binding protein (VDBP), von Willebrand factor (vWF)), AXL receptor tyrosine kinase (AXL), chemokine CC-4 (HCC-4), FASLG receptor (FAS), hepatocyte growth factor (HGF), TNF-related apoptosis-inducing ligand receptor 3 (TRAIL-R3)), alpha-fetoprotein (AFP), cancer antigen 125 (CA-125), cancer antigen 19-9 (CA-19-9), carcinoembryonic antigen (CEA), human chorionic gonadotropin beta (hCG), neuron-specific enolase (NSE)), matrix metalloproteinase-1 (MMP-1), matrix metalloproteinase-7 (MMP-7), matrix metalloproteinase-9, total (MMP-9, total), angiopoietin-1 (ANG-1), carbonic anhydrase 9 (CA-9), decorin, interleukin-18-binding protein (IL-18bp), platelet endothelial cell adhesion molecule (PECAM-1), pulmonary surfactantassociated protein D (SP-D).

\section{Statistical Analyses}

Continuous variables are presented as mean \pm standard deviation when normally distributed or as median (standard deviation). Qualitative variables are presented as absolute and relative frequencies. Statistical differences between three groups considering continuous or categorical variables have been established using one-way Analysis of Variance (ANOVA, assuming normality) with Bonferroni correction as post-hoc test, KruskalWallis test or chi-squared test, respectively. Differences between two groups were analyzed by two-sided $T$-test. For bivariate correlations, the Pearson's $\mathrm{R}$ is reported. A correlation matrix was generated by using $\mathrm{R}$ language (version 3.6.1) and plotted using ggplot2 library. For plotting, only the absolute correlation values $>0.3$ were retained. A linear discriminant analysis was performed in SPSS version 27.0 to test whether the serum markers identified above can be used to build a model that indicates increased risk of mortality. For every cytokine measured, tertiles were built and univariate logistic regression analyses performed to assess the association between cytokine tertiles and mortality. Subsequently, individual ROC analyses on the distinct models was performed. Variables with an AUC $>0.8$ were selected as predictors for mortality. A score was developed from these variables. For this purpose, the sum of the individual tertiles of each cytokine was derived. Univariate logistic regression analysis was performed to determine the association between the score and the risk of mortality.

Neural network analysis (SPPS module multilayer perceptron, MLP, one hidden layer) was performed using "death" as dependent variable and the biomarkers with different serum concentrations in survivors vs nonsurvivors as covariates. A two-sided $P$ value of less than 0.05 was considered statistically significant. Statistical analyses were performed using SPSS version 27.0. Dimension reduction and visualization of highdimensional profiles have additionally been carried out using the Uniform Manifold Approximation and Projection (UMAP) by using the R UMAP package. Input data were z-scaled before computing the UMAP. The number of components was set to 2, and the Euclidean distance was used. The computations for the UMAP used R 4.0.3 GUI 1.73 Catalina build (7892). We 
Table I Distribution of Age, Sex, and BMI Between the Study Groups

\begin{tabular}{|c|c|c|c|c|}
\hline Item & Control & Pneumonia & COVID-19 & Statistical Significance \\
\hline Patient number & 28 & 23 & 35 & - \\
\hline Sex, \% male & 100 & 100 & 74 & $* *$ \\
\hline Age & $62.42(2.14)$ & $64.61(3.11)$ & $63.86(3.18)$ & - \\
\hline BMI & $26.30(0.99)$ & $27.27(2.22)$ & $27.08(1.31)$ & - \\
\hline TISS & - & $40 \pm 2$ & $40 \pm 3$ & - \\
\hline SAPS II & - & $12 \pm 1$ & $17 \pm 2$ & - \\
\hline Mortality rate (\%) & 0 & 8.7 & 31.4 & - \\
\hline
\end{tabular}

Notes: Data are median (SD) and $\mathrm{n}(\%)$. ** Indicates $\mathrm{p}<0.0 \mathrm{I}$ as calculated by Kruskal-Wallis test; Chi-square test was used for categorical data.

applied the PERMANOVA function in the R PERMANOVA package. The data were scaled by column, ie, the column means were subtracted and columns were divided by its standard deviation using the IniTransform function. The number of permutations was increased from the standard value (1000 permutations) by two orders of magnitude.

\section{Role of the Funding Source}

This work was supported by grants of the Rolf M. Schwiete Stiftung (2020-013), the Saarland University, and The State of Saarland. Protein biomarker assays have been performed in collaboration with Myriad RBM.

The funders of the study had no role in study design, data collection, data interpretation, or writing of the report. The corresponding author had full access to all data in the study and had final responsibility for the decision to submit for publication.

\section{Results}

\section{The Blood Inflammatory Profile Differs Between COVID-19 and Conventional Pneumonia}

As a first step we compared the concentrations of blood mediators between patients with pneumonia, COVID-19 and a control group of patients undergoing nonpulmonary surgery. Table 1 summarizes the main characteristics of the patients in these groups and shows that the three groups did not differ with respect to age or body mass index (BMI). Supplementary Table S1 summarizes the clinical characteristics of all patients. Only male patients were recruited for the control and pneumonia groups to avoid sex-related changes of metabolic parameters. We analyzed the data from the measurements and found that the concentrations of IL-1-alpha,
IL-3，IL-4，IL-7，IL-12p70，TNF-alpha, and TNF-beta were below the detection threshold. These markers were excluded from further analysis.

A direct comparison of results from the three groups showed distinct patterns of elevated venous markers when analyzed by ANOVA with Bonferroni correction as post-hoc test. The three groups differ with regard to the concentrations of various cytokines: CRP, AAT, B2M, BDNF, EN-RAGE, fibrinogen, haptoglobin, IgA, IgM, ICAM-1, IL-1b, IL-8, MIP-1alpha, MMP-3, MMP-9, MCP-1, myoglobin, PAI-1, PARC, SAP, SCF, RANTES, TIMP-1, VCAM-1, vWF, AXL, HCC-4, HGF, MMP-7, MMP-9, NSE, PECAM-1, SPD, A2Macro, IL-18, CA-125, CA-9, decorin, IL-18bp and TRAIL-R3. The data are summarized in Table 2. Figure 1A displays a selection of markers with significant differences.

Comparing COVID-19 to conventional pneumonia revealed significant differences with increased concentrations of BDNF, MMP-9, and NSE, while A2Macro, B2M, IgA, MIP1alpha, MMP-3, myoglobin, SCF, TNFR2, vWF, AXL, CA-125, CA-9, HCC-4, decorin, MMP-7, SPD, TRAIL-R3 were decreased in COVID-19 as compared to pneumonia patients. No significant differences were found for IL-6, or FRTN. As compared to the control group, COVID-19 patients showed increased concentrations of CRP, fibrinogen, IgM, PECAM-1, NSE, AAT, N-RAGE, IL-18, IL-18bp, MCP-1, PAI-1, and SAP. Using a UMAP approach, we classified individuals of all three groups based on their biomarker levels. This procedure resulted in significant segregation of the three groups (Figure 1B). A PERMANOVA analysis was performed in the R PERMANOVA package (permutations increased from the standard value (1000 permutations) by two orders of magnitude) and the respective $\mathrm{p}$-value was $\mathrm{p}=1 * 10^{-5}$. 
Table 2 Serum Concentrations of Blood Proteins in Patients with Pneumonia, COVID-19 and Control Patients Without Lung Disease Undergoing Elective Surgery

\begin{tabular}{|c|c|c|c|c|}
\hline Analyte & Control (A) & Pneumonia (B) & COVID-19 (C) & Statistical Significance \\
\hline N & 28 & 23 & 35 & - \\
\hline Albumin $[g / L]$ & $33.16 \pm 0.97$ & $27.96 \pm 1.76$ & $32.49 \pm 1.69$ & - \\
\hline Total protein $[\mathrm{g} / \mathrm{L}]$ & $51.36 \pm 1.63$ & $50.83 \pm 2.8$ & $57.86 \pm 1.88$ & - \\
\hline Adiponectin $[\mu \mathrm{g} / \mathrm{mL}]$ & $5.31 \pm 0.44$ & $6.4 \pm 0.78$ & $6.77 \pm 0.79$ & - \\
\hline AAT $[\mathrm{mg} / \mathrm{mL}]$ & $1.85 \pm 0.11$ & $3.41 \pm 0.31$ & $3.03 \pm 0.19$ & $\begin{array}{l}\mathrm{B}>\mathrm{A} * * * \\
\mathrm{C}>\mathrm{A} * * *\end{array}$ \\
\hline A2Macro $[\mathrm{mg} / \mathrm{mL}]$ & $2.5 \pm 0.14$ & $2.77 \pm 0.28$ & $2.11 \pm 0.1$ & $\mathrm{~B}>\mathrm{C} *$ \\
\hline Lp(a) $[\mu \mathrm{g} / \mathrm{mL}]$ & $257.55 \pm 68.59$ & $295.7 \pm 66.69$ & $153.74 \pm 38.47$ & - \\
\hline B2M $[\mu \mathrm{g} / \mathrm{mL}]$ & $2.91 \pm 0.29$ & $9.57 \pm 1.4$ & $5.45 \pm 0.86$ & $\begin{array}{l}\mathrm{B}>\mathrm{A} * * * \\
\mathrm{~B}>\mathrm{C} * *\end{array}$ \\
\hline BDNF [ng/mL] & $11.78 \pm 0.89$ & $4.76 \pm 0.6$ & $10.41 \pm 1.29$ & $\begin{array}{l}\mathrm{A}>\mathrm{B} * * * \\
\mathrm{C}>\mathrm{B} * *\end{array}$ \\
\hline CRP $[\mu \mathrm{g} / \mathrm{mL}]$ & $43.1 \pm 13.47$ & $242.22 \pm 37.04$ & $189.81 \pm 27.09$ & $\begin{array}{l}\mathrm{B}>\mathrm{A} * * * \\
\mathrm{C}>\mathrm{A} * *\end{array}$ \\
\hline C3 $[\mathrm{mg} / \mathrm{mL}]$ & $1.21 \pm 0.08$ & $1.38 \pm 0.12$ & $1.36 \pm 0.07$ & - \\
\hline EN-RAGE [ng/mL] & $250.77 \pm 46.84$ & $950.57 \pm 153.36$ & $871.77 \pm 125.45$ & $\begin{array}{l}\mathrm{B}>\mathrm{A} * * \\
\mathrm{C}>\mathrm{A} * *\end{array}$ \\
\hline Eotaxin-I $[\mathrm{pg} / \mathrm{mL}]$ & $154.58 \pm 19.09$ & $177.61 \pm 32.18$ & $169.2 \pm 24.35$ & - \\
\hline Factor VII [ng/mL] & $290.96 \pm 22.32$ & $355.09 \pm 32.06$ & $338.37 \pm 20.82$ & - \\
\hline FRTN [ng/mL] & $1439.23 \pm 428.85$ & $2236.35 \pm 484.33$ & $2904.2 \pm 641.14$ & - \\
\hline Fibrinogen $[\mathrm{mg} / \mathrm{mL}]$ & $0.01 \pm 0$ & $0.04 \pm 0.01$ & $0.03 \pm 0$ & $\begin{array}{l}B>A * * \\
C>A *\end{array}$ \\
\hline GM-CSF [pg/mL] & $9.38 \pm 0.38$ & $9.52 \pm 0.52$ & $9.77 \pm 0.77$ & - \\
\hline Haptoglobin [mg/mL] & $2.29 \pm 0.35$ & $5.46 \pm 0.93$ & $4.03 \pm 0.46$ & $\mathrm{~B}>\mathrm{A} * *$ \\
\hline $\operatorname{lgA}[\mathrm{mg} / \mathrm{mL}]$ & $3.33 \pm 0.32$ & $4.76 \pm 0.62$ & $3.31 \pm 0.32$ & $\mathrm{~B}>\mathrm{C} *$ \\
\hline $\operatorname{lgM}[\mathrm{mg} / \mathrm{mL}]$ & $2.22 \pm 0.2$ & $3.46 \pm 0.43$ & $3.49 \pm 0.33$ & $\begin{array}{l}B>A * \\
C>A *\end{array}$ \\
\hline ICAM-I [ng/mL] & $92.15 \pm 9.43$ & $199.61 \pm 19.62$ & $145.6 \pm 22.86$ & $\mathrm{~B}>\mathrm{A} * *$ \\
\hline IFN-gamma [pg/mL] & $2.62 \pm 0.12$ & $2.5 \pm 0$ & $3.92 \pm 0.96$ & - \\
\hline IL-I beta $[\mathrm{pg} / \mathrm{mL}]$ & $8.19 \pm 0.7$ & $11.01 \pm 0.87$ & $10.44 \pm 0.56$ & $B>A *$ \\
\hline IL-Ira [pg/mL] & $490.46 \pm 212.31$ & $599.91 \pm 172.38$ & $600.11 \pm 84.6$ & - \\
\hline IL-2 [pg/mL] & $26.6 \pm 1.1$ & $27.26 \pm 1.76$ & $25.5 \pm 0$ & - \\
\hline IL-5 [pg/mL] & $5.83 \pm 0.33$ & $7.15 \pm 1.32$ & $5.5 \pm 0$ & - \\
\hline IL-6 [pg/mL] & $22 \pm 8.27$ & $46.05 \pm 13.28$ & $108.16 \pm 46.33$ & - \\
\hline IL-8 [pg/mL] & $42.79 \pm 9.48$ & $99.22 \pm 18.82$ & $63.1 \pm 10.08$ & $B>A *$ \\
\hline
\end{tabular}

(Continued) 
Table 2 (Continued).

\begin{tabular}{|c|c|c|c|c|}
\hline Analyte & Control (A) & Pneumonia (B) & COVID-19 (C) & Statistical Significance \\
\hline IL-I0 [pg/mL] & $25.19 \pm 7.34$ & $20.65 \pm 3.22$ & $20.23 \pm 2.96$ & - \\
\hline IL-12p40 [ng/mL] & $0.59 \pm 0.06$ & $0.75 \pm 0.06$ & $0.69 \pm 0.04$ & - \\
\hline IL-I7 [pg/mL] & $1.58 \pm 0.21$ & $2 \pm 0.31$ & $1.81 \pm 0.21$ & - \\
\hline IL- 18 [pg/mL] & $332.48 \pm 58.24$ & $936.5 \pm 187.53$ & $855.4 \pm 144.83$ & $\begin{array}{l}B>A * \\
C>A *\end{array}$ \\
\hline MIP-I alpha [pg/mL] & $26.81 \pm 2.99$ & $60 \pm 9.45$ & $29.09 \pm 2.94$ & $\begin{array}{l}\mathrm{B}>\mathrm{A} * * * \\
\mathrm{~B}>\mathrm{C} * * *\end{array}$ \\
\hline MIP-I beta $[\mathrm{pg} / \mathrm{mL}]$ & $401.35 \pm 56.26$ & $686.78 \pm 201.81$ & $573.54 \pm 63.52$ & - \\
\hline MMP-3 [ng/mL] & $7.37 \pm 1.34$ & $20.2 \pm 3.43$ & $8.66 \pm 1.11$ & $\begin{array}{l}\mathrm{B}>\mathrm{A} * * * \\
\mathrm{~B}>\mathrm{C} * * *\end{array}$ \\
\hline MMP-9 [ng/mL] & $35.5 \pm 2.78$ & $46.57 \pm 3.49$ & $38.74 \pm 2.58$ & $B>A *$ \\
\hline MCP-I [pg/mL] & $473.83 \pm 60.27$ & $957.74 \pm 175.78$ & $|274.9| \pm 283.05$ & $C>A *$ \\
\hline Myoglobin [ng/mL] & $108.69 \pm 17.2$ & $179.96 \pm 15.58$ & $109.31 \pm 15.84$ & $\begin{array}{l}\mathrm{B}>\mathrm{A} * \\
\mathrm{~B}>\mathrm{C} *\end{array}$ \\
\hline PAI-I [ng/mL] & $217.85 \pm 22.86$ & $253.41 \pm 26.81$ & $353.6 \pm 33.72$ & $C>A * *$ \\
\hline PARC $[\mathrm{ng} / \mathrm{mL}]$ & $187.85 \pm 31.35$ & $319.52 \pm 52.11$ & $229.69 \pm 24.21$ & $B>A *$ \\
\hline SAP $[\mu g / m L]$ & $15.38 \pm 0.93$ & $24.17 \pm 2.23$ & $20.63 \pm 1.02$ & $\begin{array}{l}\mathrm{B}>\mathrm{A} * * * \\
\mathrm{C}>\mathrm{A} *\end{array}$ \\
\hline $\mathrm{SCF}[\mathrm{pg} / \mathrm{mL}]$ & $438.98 \pm 35.14$ & $966.04 \pm 98.35$ & $563.67 \pm 41.53$ & $\begin{array}{l}\mathrm{B}>\mathrm{A} * * * \\
\mathrm{~B}>\mathrm{C} * * *\end{array}$ \\
\hline RANTES [ng/mL] & $26.43 \pm 3.01$ & $16.88 \pm 2.35$ & $20.62 \pm 1.71$ & $\mathrm{~A}>\mathrm{B} *$ \\
\hline TBG $[\mu \mathrm{g} / \mathrm{mL}]$ & $44.19 \pm 1.83$ & $48.52 \pm 2.83$ & $45.29 \pm 2.34$ & - \\
\hline TIMP-I [ng/mL] & $298.27 \pm 38.77$ & $474.87 \pm 30.13$ & $404.03 \pm 39.84$ & $B>A * *$ \\
\hline TNFR2 [ng/mL] & $110.88 \pm 93.99$ & $64.48 \pm 8.43$ & $34.87 \pm 7.07$ & - \\
\hline VCAM-I [ng/mL] & $947.04 \pm 68.15$ & $1568.09 \pm 142.19$ & $1291.77 \pm 95.44$ & $\mathrm{~B}>\mathrm{A} * * *$ \\
\hline VEGF $[\mathrm{pg} / \mathrm{mL}]$ & $313.23 \pm 44.04$ & $421.7 \pm 62.61$ & $486.4 \pm 49.45$ & - \\
\hline $\operatorname{VDBP}[\mu \mathrm{g} / \mathrm{mL}]$ & $250.31 \pm 16.54$ & $283.7 \pm 26.06$ & $281.37 \pm 16.26$ & - \\
\hline $\mathrm{vWF}[\mu \mathrm{g} / \mathrm{mL}]$ & $343.92 \pm 28.95$ & $575.35 \pm 45.67$ & $440.06 \pm 40.27$ & $\mathrm{~B}>\mathrm{A} * *$ \\
\hline AFP $[\mathrm{ng} / \mathrm{mL}]$ & $14.28 \pm 13.63$ & $0.83 \pm 0.16$ & $0.56 \pm 0.04$ & - \\
\hline ANG-I [ng/mL] & $36.12 \pm 2.83$ & $32.79 \pm 3.87$ & $41.96 \pm 3.39$ & - \\
\hline $\mathrm{AXL}[\mathrm{ng} / \mathrm{mL}]$ & $7.36 \pm 0.62$ & $10.66 \pm 1.01$ & $7.31 \pm 0.73$ & $\begin{array}{l}B>A * \\
B>C *\end{array}$ \\
\hline CA-I25 [U/mL] & $10.53 \pm 3.8$ & $35.70 \pm 8.71$ & $7.07 \pm 1.26$ & $\begin{array}{l}\mathrm{B}>\mathrm{A} * * \\
\mathrm{~B}>\mathrm{C} * * *\end{array}$ \\
\hline CA-19-9 [U/mL] & $47.28 \pm 20.17$ & $33.14 \pm 11.35$ & $22.22 \pm 5.97$ & - \\
\hline CA-9 [ng/mL] & $0.35 \pm 0.09$ & $0.53 \pm 0.08$ & $0.34 \pm 0.05$ & $\mathrm{~B}>\mathrm{C} *$ \\
\hline
\end{tabular}


Table 2 (Continued).

\begin{tabular}{|c|c|c|c|c|}
\hline Analyte & Control (A) & Pneumonia (B) & CoVID-19 (C) & Statistical Significance \\
\hline CEA $[\mathrm{ng} / \mathrm{mL}]$ & $1.99 \pm 0.95$ & $3.84 \pm 0.95$ & $2.20 \pm 0.33$ & - \\
\hline $\mathrm{HCC}-4[\mathrm{ng} / \mathrm{mL}]$ & $4.26 \pm 0.32$ & $5.93 \pm 0.39$ & $3.04 \pm 0.32$ & $\begin{array}{l}\mathrm{A}>\mathrm{C} * \\
\mathrm{~B}>\mathrm{A} * * \\
\mathrm{~B}>\mathrm{C} * * *\end{array}$ \\
\hline Decorin $[\mathrm{ng} / \mathrm{mL}]$ & $2.26 \pm 0.19$ & $3.21 \pm 0.22$ & $2.58 \pm 0.22$ & $B>A *$ \\
\hline FAS $[\mathrm{ng} / \mathrm{mL}]$ & $29.82 \pm 3.84$ & $66.26 \pm 6.4$ & $43.7 \pm 17.63$ & - \\
\hline HGF $[\mathrm{ng} / \mathrm{mL}]$ & $9.99 \pm 0.94$ & $36.75 \pm 8.03$ & $31.04 \pm 8.28$ & $B>A *$ \\
\hline $\mathrm{hCG}[\mathrm{mlU} / \mathrm{mL}]$ & $3.19 \pm 0.89$ & $2.9 \pm 0.37$ & $3.63 \pm 0.78$ & - \\
\hline IL-I8bp [ng/mL] & $11.92 \pm 0.89$ & $23.61 \pm 2.18$ & $20.19 \pm 1.84$ & $\begin{array}{l}\mathrm{B}>\mathrm{A} * * * \\
\mathrm{C}>\mathrm{A} * *\end{array}$ \\
\hline MMP-I [ng/mL] & $13.96 \pm 1.92$ & $24.58 \pm 4.51$ & $25.55 \pm 3.82$ & - \\
\hline MMP-7 [ng/mL] & $7.17 \pm 1.55$ & $11.81 \pm 1.4$ & $7.97 \pm 1.04$ & $\mathrm{~B}>\mathrm{C} *$ \\
\hline MMP-9, total $[\mathrm{ng} / \mathrm{mL}]$ & $869.77 \pm 93.18$ & $899.91 \pm 87.2$ & $1247.29 \pm 107.05$ & $\begin{array}{l}\mathrm{C}>\mathrm{A} * \\
\mathrm{C}>\mathrm{B} *\end{array}$ \\
\hline NSE $[\mathrm{ng} / \mathrm{mL}]$ & $0.59 \pm 0.06$ & $1.03 \pm 0.12$ & $2.11 \pm 0.22$ & $\begin{array}{l}\mathrm{C}>\mathrm{A} * * * \\
\mathrm{C}>\mathrm{B} * * *\end{array}$ \\
\hline PECAM-I [ng/mL] & $54.85 \pm 2.84$ & $92.43 \pm 9.08$ & $77.23 \pm 5.94$ & $\begin{array}{l}\mathrm{B}>\mathrm{A} * * * \\
\mathrm{C}>\mathrm{A} *\end{array}$ \\
\hline SP-D [ng/mL] & $15.7 \mid \pm 2.16$ & $73.97 \pm 14.57$ & $34.19 \pm 4.73$ & $\begin{array}{l}\mathrm{B}>\mathrm{A} * * * \\
\mathrm{~B}>\mathrm{C} * * *\end{array}$ \\
\hline TRAIL-R3 [ng/mL] & $6.82 \pm 0.6$ & $16.24 \pm 2.39$ & $8.61 \pm 0.76$ & $\begin{array}{l}\mathrm{B}>\mathrm{A} * * * \\
\mathrm{~B}>\mathrm{C} * * *\end{array}$ \\
\hline
\end{tabular}

Notes: Data are median $\pm S D$. *Indicates $p<0.05$, ${ }^{*} \mathrm{p}<<0.005,{ }^{* * *} \mathrm{p}<0.00 \mathrm{I}$ as calculated using one-way Analysis of Variance (ANOVA, assuming normality) with Bonferroni correction as post-hoc test. The column on the right indicated differences between groups based on Bonferroni-adjusted post-hoc analysis between analytes from (A) control, (B) pneumonia, and (C) COVID-19 patients.

\section{Factors Associated with Disease Severity in COVID-I9 Patients}

COVID-19 is a dynamic disease that often progresses towards respiratory failure and systemic inflammation and shock. The differences of blood concentrations between the disease severity stages (normal care vs intensive care treatment) were analyzed (Table 3A). Figure 2A displays the significantly altered biomarkers. More severely sick patients requiring ICU treatment had increased levels of AAT, CRP, EN-RAGE, IL-1ra, IL-8, IL-10, IL-18, MCP-1, myoglobin, SAP, TIMP-1, vWF, decorin, and HGF, but decreased blood concentrations of albumin, total protein, adiponectin, A2Macro, BDNF, IL-17, and RANTES.

The COVID-19 group comprised both female and male patients. We compared blood concentrations of all markers and found significant differences for albumin, AAT, CRP, EN-RAGE, FRTN, IL-1ra, IL-10, myoglobin, TIMP-1, VCAM-1, vWF, AFP, decorin, MMP-7, and NSE. Severity indices TISS and SAPS II were not different between both groups. The data are summarized in Supplementary Table S2.

To further evaluate the association between serum markers and disease severity, we measured the ICU scores SAPS II (Simplified Acute Physiology Score) and TISS (Therapeutic intervention scoring system) in COVID-19 patients. Supplementary Table S3 presents results of bivariate correlation analysis, Figure 2B displays a summary correlation plot.

\section{Factors Associated with Death}

One important goal of the use of biomarkers is to identify patients with increased risk of dying. As no death occurred 
A

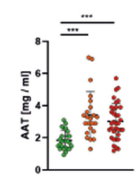

- Contro

- Pneumonia

- COVID-19
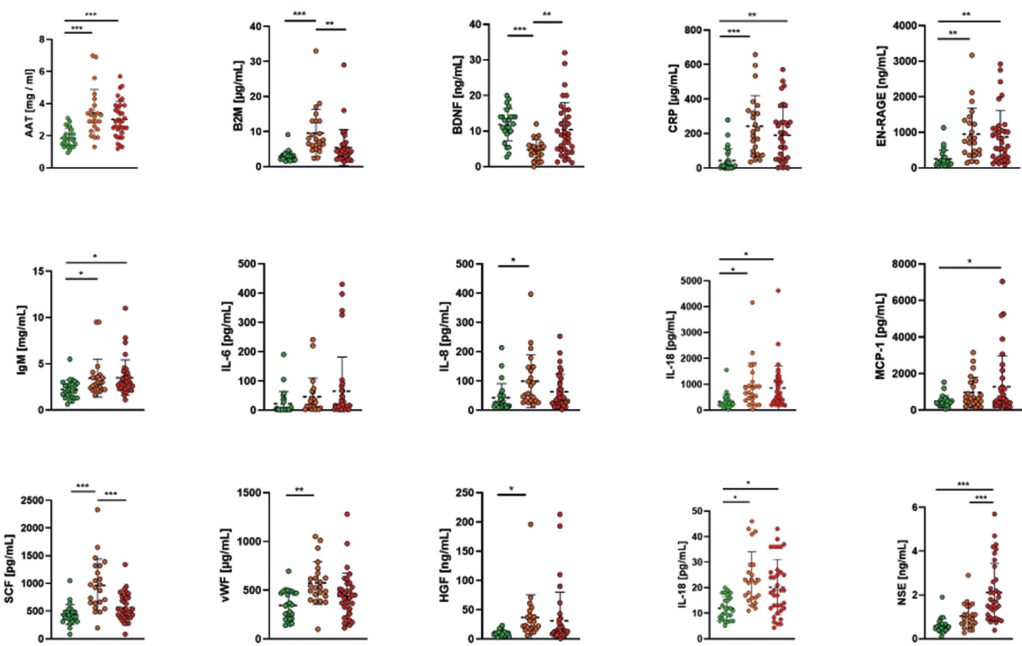

B

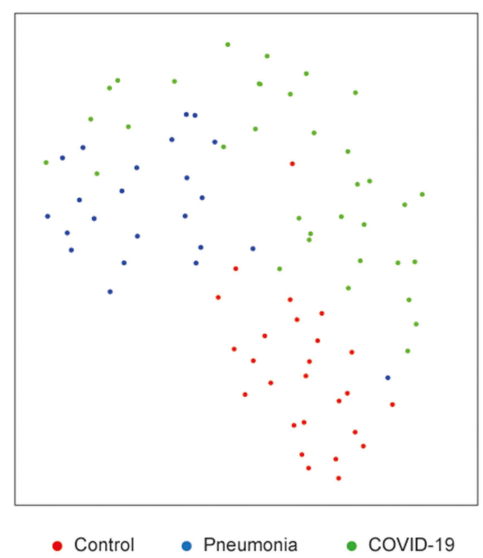

Figure I Serum markers discriminate between control, pneumonia, or COVID-19. (A) Serum concentrations of biomarkers that showed differences between control, pneumonia, or COVID-19 groups. $*_{p}<0.05$, **p $<0.005$, *** $*_{p}<0.001$ as calculated using one-way Analysis of Variance (ANOVA, assuming normality) with Bonferroni correction as post-hoc test. (B) UMAP dimension reduction integrating all detectable biomarkers shows segregation the three groups. We clustered the individuals by 3 -means clustering and computed for each cluster how many individuals from the three groups were contained. Following this clustering we computed Fisher's Exact test on the $3 \times 3$ contingency table, validating a significant clustering $(p<0.000 \mathrm{I})$.

in the control group and few in the pneumonia group, we identified factors associated with mortality only in the COVID-19 group (Table 3B). Figure 3A displays the significantly changed biomarkers between the survivors and the deceased patients. $T$-test identified increased levels of eotaxin, IL-1beta, IL-1ra, IL-8, IL-10, MCP-1， SCF, TIMP-1, CA-9, CEA, IL-18p. Decreased concentrations were found for albumin, adiponectin, BDNF, and ANG1. No significant differences were found for BMI or age. A UMAP analysis (Figure 3B) shows a significant separation between these two groups.

A linear discriminant analysis was performed to test whether the serum markers identified above can be used to build a model that predicts mortality. The canonical discriminant functions revealed an Eigenvalue of 2.964 and a canonical correlation of 0.865 (Wilks-Lambda 0.252 , Chi-quadrat $\mathrm{P}=0.014$ ) indicated a valid model with high standardized canonical discriminant function coefficients for IL-6 (0.532), IL-8 (0.467), MCP-1 (0.625), SCF (0.567), TIMP-1 $(-0.920)$, decorin $(-0.737)$, and HGF (0.614). This model resulted in a correct classification of $97.1 \%$ of the original cases and $73.5 \%$ of the crossvalidation cases.

While the number of cases is low, we used several rounds neural network analysis (SPPS module multilayer perceptron, MLP, one hidden layer) using "death" as dependent variable and the biomarkers with different serum concentrations in survivors vs non-survivors as covariates. The analysis was performed four times using different random training sets and resulted in: 1. Analysis: correct prediction in the training/test set of $88.5 / 87.5 \%$ (with the 5 most relatively important variables: IL-6, Eotaxin, IL-8, IL-1ra, MCP-1); 2. Analysis 100/100\% correct prediction (MCP-1, SCF, BDNF, Eotaxin, Decorin); 3. Analysis 95.5/91.7\% correct prediction (BDNF, IL-10, CA-9, MCP-1, Adiponectin); 4. Analysis 95.8/100\% correct prediction (SCF, BDNF, IL18bp, IL8, Age).

Finally, a score combining IL-1ra, IL-8, IL-10, MCP-1, SCF, and CA-9 was associated with significantly higher mortality (OR: 2.09 (95\% CI 1.27-3.43, P=0.004)) with an AUC of 0.929 .

\section{Discussion}

The main findings of this study are that severe COVID-19 differs from conventional pneumonia by a specific blood cytokine profile. Several serum mediators are correlated with disease severity and outcome. While some blood biomarkers are significantly elevated in severe COVID19, a classical "cytokine storm" as seen in other conditions was not observed. Several biomarkers are associated with disease severity and risk of death. 
Table 3 Biomarkers Significantly Increased in Patients with Severe COVID-19 Disease (A) or in Patients Who Died During the Course of Disease (B)

\begin{tabular}{|c|c|c|c|c|}
\hline \multirow[t]{2}{*}{ Analyte } & \multicolumn{2}{|c|}{ Severity (A) } & \multicolumn{2}{|c|}{ Survivor vs Non-Survivor (B) } \\
\hline & Complicated & Critical & Survivor & Non-Survivor \\
\hline $\mathrm{N}$ & 25 & 10 & 24 & II \\
\hline \multirow[t]{2}{*}{ TISS } & $18.75 \pm 5.75$ & $15.38 \pm 1.35$ & $12.6 \pm 2.29$ & $19.29 \pm 2.64$ \\
\hline & \multicolumn{2}{|c|}{$p>0.05$} & \multicolumn{2}{|c|}{$p>0.05$} \\
\hline \multirow[t]{2}{*}{ SAPS } & $38.00 \pm 6.62$ & $41.50 \pm 3.74$ & $34.60 \pm 4.86$ & $44.43 \pm 3.74$ \\
\hline & \multicolumn{2}{|c|}{$p>0.05$} & \multicolumn{2}{|c|}{$p>0.05$} \\
\hline \multirow[t]{2}{*}{ Albumin $[g / L]$} & $35.13 \pm 2.01$ & $24.90 \pm 2.06$ & $35.13 \pm 1.89$ & $27 \pm 3.14$ \\
\hline & \multicolumn{2}{|c|}{$p=0.005$} & \multicolumn{2}{|c|}{$P=0.026$} \\
\hline \multirow[t]{2}{*}{ Total protein $[\mathrm{g} / \mathrm{L}]$} & $61.65 \pm 1.71$ & $48.60 \pm 3.80$ & $60.39 \pm 2.10$ & $52.73 \pm 3.72$ \\
\hline & \multicolumn{2}{|c|}{$p=0.001$} & \multicolumn{2}{|c|}{$p=0.063$} \\
\hline \multirow[t]{2}{*}{ Adiponectin $[\mu \mathrm{g} / \mathrm{mL}]$} & $7.41 \pm 0.93$ & $4.13 \pm 0.51$ & $7.86 \pm 1.12$ & $4.77 \pm 0.55$ \\
\hline & \multicolumn{2}{|c|}{$P=0.032$} & \multicolumn{2}{|c|}{$P=0.019$} \\
\hline \multirow[t]{2}{*}{ AAT $[\mathrm{mg} / \mathrm{mL}]$} & $2.7 \pm 0.20$ & $3.87 \pm 0.32$ & $3.01 \pm 0.24$ & $3.1 \pm 0.34$ \\
\hline & \multicolumn{2}{|c|}{$p=0.004$} & \multicolumn{2}{|c|}{$P=0.831$} \\
\hline \multirow[t]{2}{*}{ A2Macro $[\mathrm{mg} / \mathrm{mL}]$} & $2.24 \pm 0.11$ & $1.77 \pm 0.24$ & $2.20 \pm 0.10$ & $1.93 \pm 0.24$ \\
\hline & \multicolumn{2}{|c|}{$P=0.041$} & \multicolumn{2}{|c|}{$P=0.323$} \\
\hline \multirow[t]{2}{*}{$\operatorname{Lp}(\mathrm{a})[\mu \mathrm{g} / \mathrm{mL}]$} & $184.96 \pm 56.54$ & $99.40 \pm 28.09$ & $192.30 \pm 56.36$ & $80.55 \pm 22.05$ \\
\hline & \multicolumn{2}{|c|}{$P=0.341$} & \multicolumn{2}{|c|}{$p=0.190$} \\
\hline \multirow[t]{2}{*}{ B2M $[\mu \mathrm{g} / \mathrm{mL}]$} & $5.52 \pm 1.27$ & $5.61 \pm 0.84$ & $4.79 \pm 1.17$ & $7.11 \pm 1.17$ \\
\hline & \multicolumn{2}{|c|}{$P=0.964$} & \multicolumn{2}{|c|}{$P=0.226$} \\
\hline BDNF [ng/mL] & $12.48 \pm 1.60$ & $4.22 \pm 0.75$ & $12.35 \pm 1.73$ & $6.02 \pm 1.19$ \\
\hline & & 006 & & 005 \\
\hline CRP $[\mu \mathrm{g} / \mathrm{mL}]$ & $132.5 \pm 28.92$ & $333.30 \pm 37.68$ & $178.10 \pm 33.76$ & $226.09 \pm 48.77$ \\
\hline & & 004 & & 425 \\
\hline $\mathrm{C} 3[\mathrm{mg} / \mathrm{mL}]$ & $1.36 \pm 0.07$ & $1.27 \pm 0.14$ & $1.39 .00 \pm 0.08$ & $1.27 \pm 0.12$ \\
\hline & & & & 403 \\
\hline EN-RAGE $[\mathrm{ng} / \mathrm{mL}]$ & $606.30 \pm 123.08$ & $1484.00 \pm 250.40$ & $812.00 \pm 144.24$ & $1048.73 \pm 260.16$ \\
\hline & & & & 395 \\
\hline Eotaxin-I [pg/mL] & $160.09 \pm 30.63$ & $198.20 \pm 48.95$ & $122.04 \pm 17.62$ & $269 \pm 59.35$ \\
\hline & & & & 036 \\
\hline Factor VII [ng/mL] & $348.43 \pm 27.7 \mathrm{I}$ & $304.40 \pm 34.48$ & $320.91 \pm 27.97$ & $365.82 \pm 29.33$ \\
\hline & & & & 330 \\
\hline FRTN [ng/mL] & $2014.57 \pm 709.46$ & $4825.30 \pm 1332.19$ & $2037.35 \pm 498.16$ & $4964.09 \pm 1629.9$ \\
\hline
\end{tabular}

(Continued) 
Table 3 (Continued).

\begin{tabular}{|c|c|c|c|c|}
\hline \multirow[t]{2}{*}{ Analyte } & \multicolumn{2}{|c|}{ Severity (A) } & \multicolumn{2}{|c|}{ Survivor vs Non-Survivor (B) } \\
\hline & Complicated & Critical & Survivor & Non-Survivor \\
\hline & \multicolumn{2}{|c|}{$P=0.051$} & \multicolumn{2}{|c|}{$p=0.112$} \\
\hline \multirow[t]{2}{*}{ Fibrinogen $[\mathrm{mg} / \mathrm{mL}]$} & $0.04 \pm 0.005$ & $0.03 \pm 0.003$ & $0.03 \pm 0.01$ & $0.03 \pm 0.00$ \\
\hline & \multicolumn{2}{|c|}{$P=0.325$} & \multicolumn{2}{|c|}{$p=0.198$} \\
\hline \multirow[t]{2}{*}{ GM-CSF $[\mathrm{pg} / \mathrm{mL}]$} & $10.17 \pm 1.17$ & $9.00 \pm 0.00$ & $10.17 \pm 1.17$ & $9.00 \pm 0.00$ \\
\hline & $P=0.518$ & & \multicolumn{2}{|c|}{$P=0.498$} \\
\hline \multirow[t]{2}{*}{ Haptoglobin [mg/mL] } & $3.74 \pm 0.60$ & $4.32 \pm 0.7$ & $4.09 \pm 0.65$ & $4.26 \pm 0.50$ \\
\hline & \multicolumn{2}{|c|}{$P=0.575$} & \multicolumn{2}{|c|}{$P=0.860$} \\
\hline \multirow[t]{2}{*}{$\operatorname{lgA}[\mathrm{mg} / \mathrm{mL}]$} & $3.00 \pm 0.27$ & $4.21 \pm 0.87$ & $3.40 \pm 0.37$ & $2.96 \pm 0.64$ \\
\hline & \multicolumn{2}{|c|}{$p=0.210$} & \multicolumn{2}{|c|}{$p=0.535$} \\
\hline \multirow[t]{2}{*}{$\lg M[\mathrm{mg} / \mathrm{mL}]$} & $3.60 \pm 0.41$ & $3.45 \pm 0.65$ & $3.85 \pm 0.45$ & $2.68 \pm 0.38$ \\
\hline & \multicolumn{2}{|c|}{$P=0.849$} & \multicolumn{2}{|c|}{$P=0.104$} \\
\hline \multirow[t]{2}{*}{ ICAM-I [ng/mL] } & $108.70 \pm|3.6|$ & $239.70 \pm 66.94$ & $119.74 \pm 18.81$ & $206 \pm 58.97$ \\
\hline & $p=0.085$ & & & 189 \\
\hline \multirow[t]{2}{*}{ IL-I beta $[\mathrm{pg} / \mathrm{mL}]$} & $10.44 \pm 0.73$ & $10.61 \pm 1.06$ & $9.62 \pm 0.67$ & $12.03 \pm 0.98$ \\
\hline & \multicolumn{2}{|c|}{$p=0.899$} & \multicolumn{2}{|c|}{$p=0.049$} \\
\hline \multirow[t]{2}{*}{ IL-Ira [pg/mL] } & $418.48 \pm 74.94$ & $1062.20 \pm 172.41$ & $441.39 \pm 85.33$ & $969.09 \pm|53.4|$ \\
\hline & \multicolumn{2}{|c|}{$P=0.005$} & \multicolumn{2}{|c|}{$P=0.003$} \\
\hline \multirow[t]{2}{*}{ IL-6 [pg/mL] } & $71.95 \pm 56.84$ & $211.40 \pm 92.09$ & $39.94 \pm 17.32$ & $260.38 \pm 135.85$ \\
\hline & \multicolumn{2}{|c|}{$P=0.195$} & \multicolumn{2}{|c|}{$p=0.138$} \\
\hline \multirow[t]{2}{*}{ IL-8 [pg/mL] } & $35.76 \pm 6.71$ & $122.60 \pm 21.63$ & $39.28 \pm 6.36$ & $116.82 \pm 22.12$ \\
\hline & & & & 006 \\
\hline IL-I0 [pg/mL] & $16.57 \pm 3.67$ & $30.60 \pm 4.72$ & $14.57 \pm 2.72$ & $33.45 \pm 5.89$ \\
\hline & & & & 011 \\
\hline IL-12p40 [ng/mL] & $0.73 \pm 0.05$ & $0.60 \pm 0.10$ & $0.65 \pm 0.05$ & $0.77 \pm 0.09$ \\
\hline & & & & 180 \\
\hline IL-17 [pg/mL] & $1.98 \pm 0.30$ & $1.30 \pm 0.00$ & $1.84 \pm 0.28$ & $1.60 \pm 0.30$ \\
\hline & & & & 600 \\
\hline IL-I8 [pg/mL] & $556.17 \pm 83.49$ & $1505.90 \pm 395.08$ & $634.09 \pm 96.95$ & $|373.00 \pm 378.6|$ \\
\hline & & & & 085 \\
\hline MIP-I alpha $[\mathrm{pg} / \mathrm{mL}]$ & $27.13 \pm 3.04$ & $32.1 \pm 7.18$ & $26.04 \pm 2.98$ & $36.45 \pm 6.66$ \\
\hline & & & & 175 \\
\hline MIP-I beta $[\mathrm{pg} / \mathrm{mL}]$ & $502.39 \pm 71.82$ & $690.5 \pm 130.62$ & $547.96 \pm 74.92$ & $660.36 \pm 125.37$ \\
\hline
\end{tabular}


Table 3 (Continued).

\begin{tabular}{|c|c|c|c|c|}
\hline \multirow[t]{2}{*}{ Analyte } & \multicolumn{2}{|c|}{ Severity (A) } & \multicolumn{2}{|c|}{ Survivor vs Non-Survivor (B) } \\
\hline & Complicated & Critical & Survivor & Non-Survivor \\
\hline & \multicolumn{2}{|c|}{$P=0.184$} & \multicolumn{2}{|c|}{$p=0.423$} \\
\hline \multirow[t]{2}{*}{ MMP-3 [ng/mL] } & $9.28 \pm 1.59$ & $7.95 \pm 1.32$ & $8.07 \pm 1.19$ & $10.17 \pm 2.53$ \\
\hline & \multicolumn{2}{|c|}{$P=0.610$} & \multicolumn{2}{|c|}{$P=0.396$} \\
\hline \multirow[t]{2}{*}{ MMP-9 [ng/mL] } & $39.48 \pm 3.40$ & $36.1 \pm 4.67$ & $36.83 \pm 3.39$ & $44.82 \pm 3.20$ \\
\hline & \multicolumn{2}{|c|}{$P=0.578$} & \multicolumn{2}{|c|}{$P=0.149$} \\
\hline \multirow[t]{2}{*}{ MCP-I $[\mathrm{pg} / \mathrm{mL}]$} & $732.96 \pm 292.33$ & $2694.90 \pm 512.90$ & $576.35 \pm 114.48$ & $2836.09 \pm 670.49$ \\
\hline & \multicolumn{2}{|c|}{$P=0.001$} & \multicolumn{2}{|c|}{$P=0.007$} \\
\hline \multirow[t]{2}{*}{ Myoglobin $[\mathrm{ng} / \mathrm{mL}]$} & $77.91 \pm 15.42$ & $195.4 \pm 28.03$ & $93.35 \pm 18.98$ & $|50.9| \pm 27.54$ \\
\hline & \multicolumn{2}{|c|}{$P=0.0004$} & \multicolumn{2}{|c|}{$P=0.094$} \\
\hline \multirow[t]{2}{*}{ PAI-I [ng/mL] } & $305.83 \pm 29.42$ & $417.4 \pm 77.93$ & $354.39 \pm 45.47$ & $368.73 \pm 49.57$ \\
\hline & \multicolumn{2}{|c|}{$P=0.108$} & \multicolumn{2}{|c|}{$P=0.848$} \\
\hline \multirow[t]{2}{*}{ PARC $[\mathrm{ng} / \mathrm{mL}]$} & $226.39 \pm 32.54$ & $253.20 \pm 38.83$ & $225.78 \pm 29.96$ & $228.73 \pm 46.01$ \\
\hline & \multicolumn{2}{|c|}{$P=0.634$} & \multicolumn{2}{|c|}{$P=0.957$} \\
\hline \multirow[t]{2}{*}{ SAP $[\mu g / m L]$} & $18.43 \pm 1.19$ & $25.00 \pm 1.12$ & $20.13 \pm 1.40$ & $21.82 \pm 1.44$ \\
\hline & \multicolumn{2}{|c|}{$P=0.002$} & \multicolumn{2}{|c|}{$p=0.462$} \\
\hline \multirow[t]{2}{*}{$\mathrm{SCF}[\mathrm{pg} / \mathrm{mL}]$} & $556.43 \pm 43.23$ & $585.95 \pm 108.10$ & $473.15 \pm 38.62$ & $760.18 \pm 78.54$ \\
\hline & \multicolumn{2}{|c|}{$P=0.76 \mathrm{I}$} & \multicolumn{2}{|c|}{$p=0.001$} \\
\hline \multirow[t]{2}{*}{ RANTES [ng/mL] } & $22.78 \pm 2.02$ & $15.27 \pm 3.03$ & $20.05 \pm 2.15$ & $20.86 \pm 3.04$ \\
\hline & & & & 829 \\
\hline TBG $[\mu \mathrm{g} / \mathrm{mL}]$ & $46.17 \pm 2.99$ & $42.9 \pm 4.39$ & $44.78 \pm 3.10$ & $45.45 \pm 3.71$ \\
\hline & & & & 898 \\
\hline TIMP-I [ng/mL] & $324.04 \pm 33.80$ & $598.4 \pm 87.38$ & $354.3 \pm 37.08$ & $526.82 \pm 91.84$ \\
\hline & & & & 045 \\
\hline TNFR2 [ng/mL] & $25.77 \pm 5.56$ & $55.2 \pm 19.99$ & $28.15 \pm 5.86$ & $51.27 \pm 18.45$ \\
\hline & & & & 137 \\
\hline VCAM-I [ng/mL] & $1198.26 \pm 119.11$ & $1496.7 \pm 165.26$ & $1191.65 \pm 117.04$ & $1523.09 \pm 166.03$ \\
\hline & & & & 115 \\
\hline VEGF [pg/mL] & $456.65 \pm 65.6 \mathrm{I}$ & $576.1 \pm 81.39$ & $450.26 \pm 63.22$ & $581.55 \pm 80.43$ \\
\hline & & & & 229 \\
\hline $\operatorname{VDBP}[\mu \mathrm{g} / \mathrm{mL}]$ & $278.13 \pm 21.49$ & $288.90 \pm 29.08$ & $273.26 \pm 23.78$ & $294.27 \pm 14.49$ \\
\hline & & & & 456 \\
\hline $\mathrm{vWF}[\mu \mathrm{g} / \mathrm{mL}]$ & $361.39 \pm 33.61$ & $632.5 \pm 89.67$ & $429.61 \pm 54.04$ & $481.36 \pm 59.19$ \\
\hline
\end{tabular}

(Continued) 
Table 3 (Continued).

\begin{tabular}{|c|c|c|c|c|}
\hline \multirow[t]{2}{*}{ Analyte } & \multicolumn{2}{|c|}{ Severity (A) } & \multicolumn{2}{|c|}{ Survivor vs Non-Survivor (B) } \\
\hline & Complicated & Critical & Survivor & Non-Survivor \\
\hline & \multicolumn{2}{|c|}{$P=0.001$} & \multicolumn{2}{|c|}{$p=0.563$} \\
\hline \multirow[t]{2}{*}{ AFP $[\mathrm{ng} / \mathrm{mL}]$} & $0.60 \pm 0.06$ & $0.49 \pm 0.00$ & $0.52 \pm 0.03$ & $0.54 \pm 0.05$ \\
\hline & \multicolumn{2}{|c|}{$P=0.105$} & \multicolumn{2}{|c|}{$P=0.780$} \\
\hline \multirow[t]{2}{*}{ ANG-I [ng/mL] } & $41.26 \pm 2.72$ & $34.55 \pm 6.37$ & $47.02 \pm 4.51$ & $32.45 \pm 3.88$ \\
\hline & \multicolumn{2}{|c|}{$P=0.260$} & \multicolumn{2}{|c|}{$P=0.048$} \\
\hline \multirow[t]{2}{*}{$\mathrm{AXL}[\mathrm{ng} / \mathrm{mL}]$} & $6.99 \pm 0.67$ & $7.75 \pm 2.06$ & $6.63 \pm 0.68$ & $8.84 \pm 1.82$ \\
\hline & \multicolumn{2}{|c|}{$P=0.651$} & \multicolumn{2}{|c|}{$P=0.174$} \\
\hline \multirow[t]{2}{*}{ CA-I25 [U/mL] } & $8.02 \pm 1.83$ & $5.67 \pm 1.22$ & $7.69 \pm 1.86$ & $5.69 \pm 1.07$ \\
\hline & \multicolumn{2}{|c|}{$P=0.425$} & \multicolumn{2}{|c|}{$p=0.480$} \\
\hline \multirow[t]{2}{*}{ CA-19-9 [U/mL] } & $23.17 \pm 8.6$ & $24.14 \pm 6.81$ & $22.4 \pm 8.54$ & $23.54 \pm 6.85$ \\
\hline & \multicolumn{2}{|c|}{$p=0.945$} & \multicolumn{2}{|c|}{$P=0.932$} \\
\hline \multirow[t]{2}{*}{ CA-9 [ng/mL] } & $0.34 \pm 0.07$ & $0.38 \pm 0.09$ & $0.26 \pm 0.06$ & $0.48 \pm 0.08$ \\
\hline & \multicolumn{2}{|c|}{$P=0.747$} & \multicolumn{2}{|c|}{$p=0.04 I$} \\
\hline \multirow[t]{2}{*}{ CEA $[\mathrm{ng} / \mathrm{mL}]$} & $1.92 \pm 0.38$ & $3.1 \pm 0.65$ & $1.58 \pm 0.3$ & $3.58 \pm 0.68$ \\
\hline & \multicolumn{2}{|c|}{$p=0.112$} & \multicolumn{2}{|c|}{$P=0.017$} \\
\hline \multirow[t]{2}{*}{$\mathrm{HCC}-4$ [ng/mL] } & $3.05 \pm 0.38$ & $3.03 \pm 0.71$ & $2.69 \pm 0.34$ & $3.56 \pm 0.69$ \\
\hline & \multicolumn{2}{|c|}{$P=0.976$} & \multicolumn{2}{|c|}{$P=0.211$} \\
\hline \multirow[t]{2}{*}{ Decorin $[\mathrm{ng} / \mathrm{mL}]$} & $2.28 \pm 0.24$ & $3.42 \pm 0.42$ & $2.27 \pm 0.18$ & $3.26 \pm 0.53$ \\
\hline & & & & 102 \\
\hline FAS [ng/mL] & $25.49 \pm 4.08$ & $91.43 \pm 60.48$ & $21.76 \pm 3.14$ & $91.64 \pm 54.6$ \\
\hline & & & & 230 \\
\hline HGF [ng/mL] & $|5.88 \pm 3.9|$ & $70.64 \pm 23.99$ & $16.47 \pm 3.05$ & $63.14 \pm 23.43$ \\
\hline & & & & 076 \\
\hline $\mathrm{hCG}[\mathrm{mlU} / \mathrm{mL}]$ & $3.74 \pm 1.13$ & $3.67 \pm 0.86$ & $3.87 \pm 1.13$ & $3.26 \pm 0.78$ \\
\hline & & & & 727 \\
\hline IL-I8bp [ng/mL] & $18.18 \pm 2.38$ & $25.60 \pm 2.67$ & $17.52 \pm 2.13$ & $26.91 \pm 2.89$ \\
\hline & & & & 016 \\
\hline MMP-I [ng/mL] & $24.98 \pm 4.46$ & $21.68 \pm 4.7$ & $24.27 \pm 5.11$ & $24.99 \pm 5.09$ \\
\hline & & & & 931 \\
\hline MMP-7 [ng/mL] & $6.47 \pm 0.7$ & $|2.21 \pm 2.9|$ & $6.85 \pm 1.10$ & $10.51 \pm 2.26$ \\
\hline & & & & 109 \\
\hline MMP-9, total $[\mathrm{ng} / \mathrm{mL}]$ & $1152.48 \pm|26.9|$ & $1389.8 \pm 225.57$ & $1372.09 \pm 130.57$ & $1080.09 \pm 172.68$ \\
\hline
\end{tabular}


Table 3 (Continued).

\begin{tabular}{|c|c|c|c|c|}
\hline \multirow[t]{2}{*}{ Analyte } & \multicolumn{2}{|c|}{ Severity (A) } & \multicolumn{2}{|c|}{ Survivor vs Non-Survivor (B) } \\
\hline & Complicated & Critical & Survivor & Non-Survivor \\
\hline & \multicolumn{2}{|c|}{$P=0.336$} & \multicolumn{2}{|c|}{$P=0.201$} \\
\hline \multirow[t]{2}{*}{ NSE [ng/mL] } & $1.85 \pm 0.27$ & $2.79 \pm 0.41$ & $1.99 \pm 0.28$ & $2.37 \pm 0.40$ \\
\hline & \multicolumn{2}{|c|}{$P=0.064$} & \multicolumn{2}{|c|}{$p=0.452$} \\
\hline \multirow[t]{2}{*}{ PECAM-I [ng/mL] } & $69.52 \pm 5.63$ & $96.7 \pm 15.09$ & $74.04 \pm 5.51$ & $87.27 \pm 14.74$ \\
\hline & \multicolumn{2}{|c|}{$P=0.118$} & \multicolumn{2}{|c|}{$P=0.416$} \\
\hline \multirow[t]{2}{*}{ SP-D [ng/mL] } & $31.47 \pm 5.76$ & $42.4 \pm 9.47$ & $34.64 \pm 5.29$ & $35.67 \pm 10.33$ \\
\hline & \multicolumn{2}{|c|}{$P=0.317$} & \multicolumn{2}{|c|}{$p=0.922$} \\
\hline \multirow[t]{2}{*}{ TRAIL-R3 [ng/mL] } & $8.34 \pm 0.92$ & $9.94 \pm 1.55$ & $8.17 \pm 0.88$ & $9.04 \pm 1.54$ \\
\hline & \multicolumn{2}{|c|}{$P=0.361$} & \multicolumn{2}{|c|}{$p=0.603$} \\
\hline
\end{tabular}

Notes: Data are median \pm SD. $P$ values were calculated using two-sided T-test.

Blood biomarkers have been used to determine disease severity or risk for deleterious outcome in conventional pneumonia. ${ }^{18-20}$ Biomarkers such as CRP, procalcitonin, and others are important tools for decision making in pneumonia patients. The identification of diagnostic, predictive or prognostic biomarkers is even more relevant in COVID-19.

There are two approaches to study the inflammatory processes and to identify biomarkers in COVID-19. One is

A $\quad$ Survivor
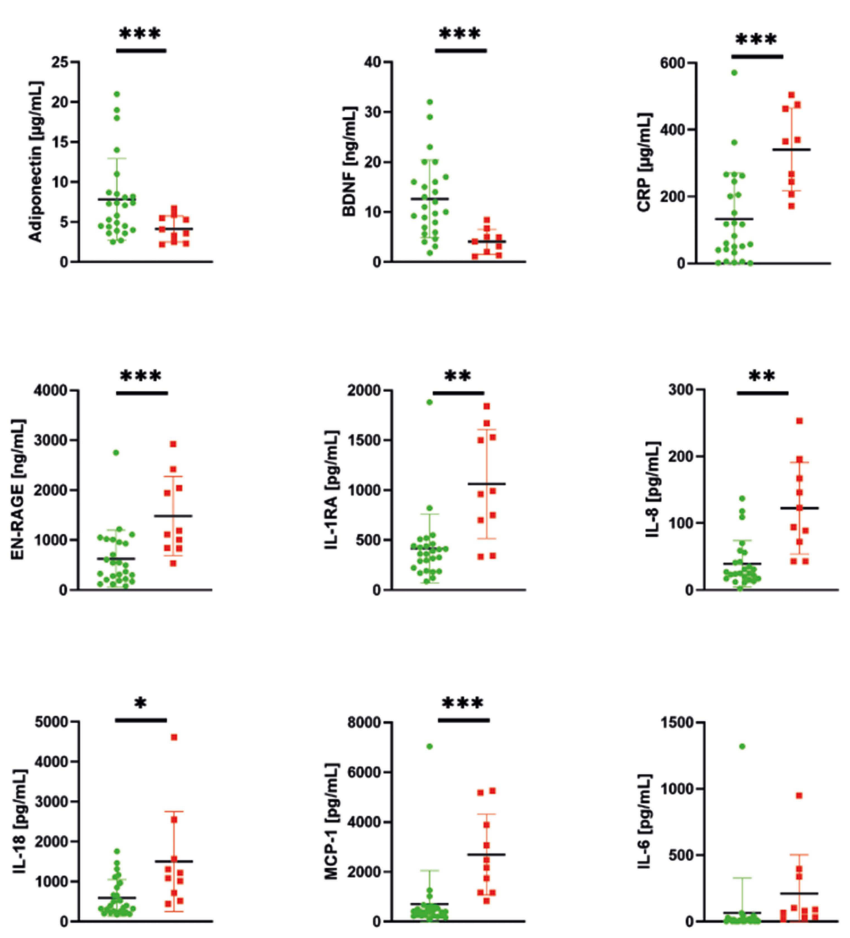

Figure 2 Biomarkers levels are associated with disease severity. (A) Biomarkers with significantly altered serum concentration in severe patients. ${ }^{*} p<0.05$, **p $<0.005$, **** $<$ $0.00 \mathrm{I}$ as calculated by two-sided T-test. (B) Biomarkers are associated with SAPS II and TISS measurements; the magnitude of Pearson's R is indicated by the color scheme.

B

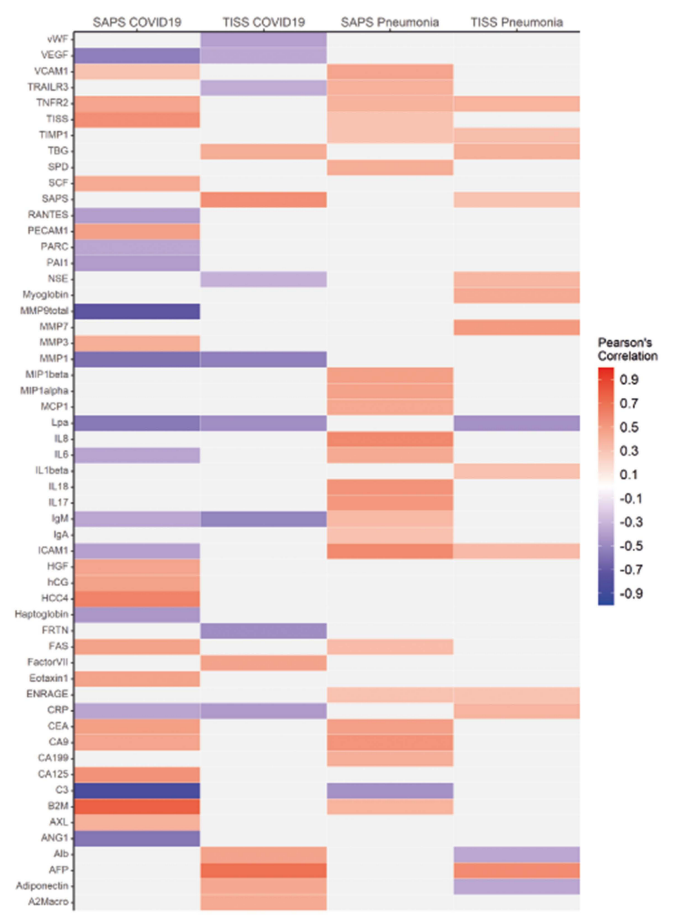


A
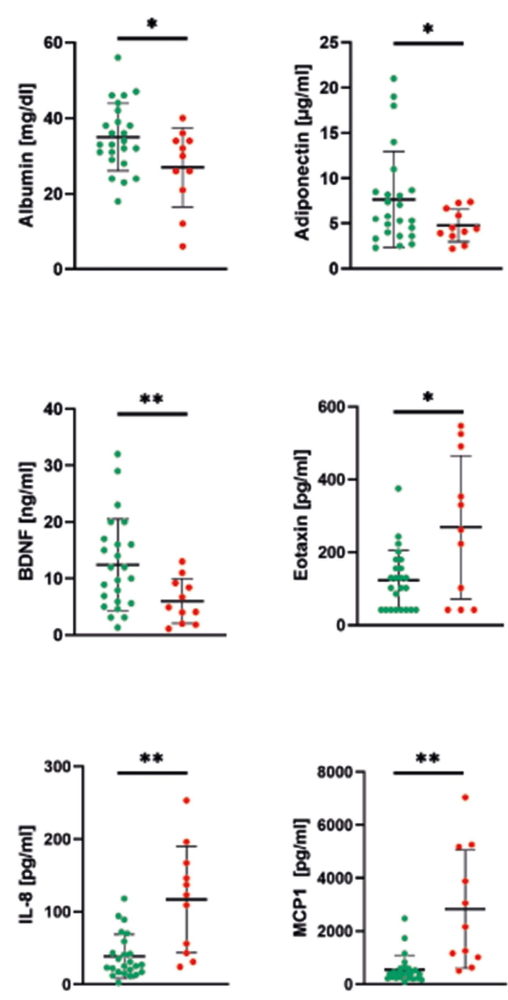
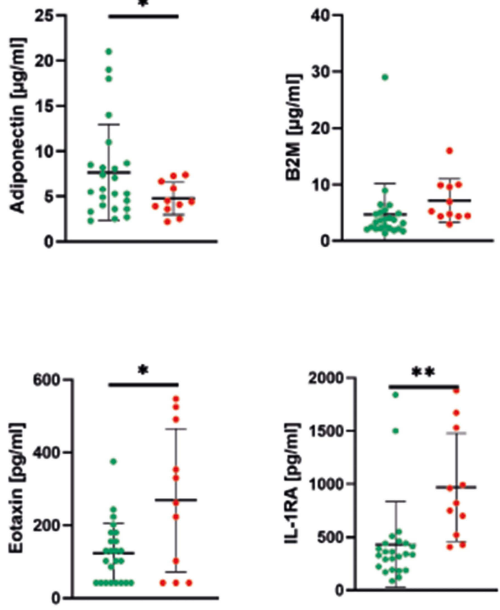

- Survivor

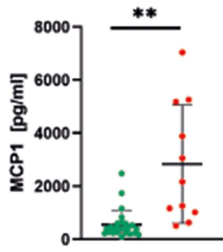

B

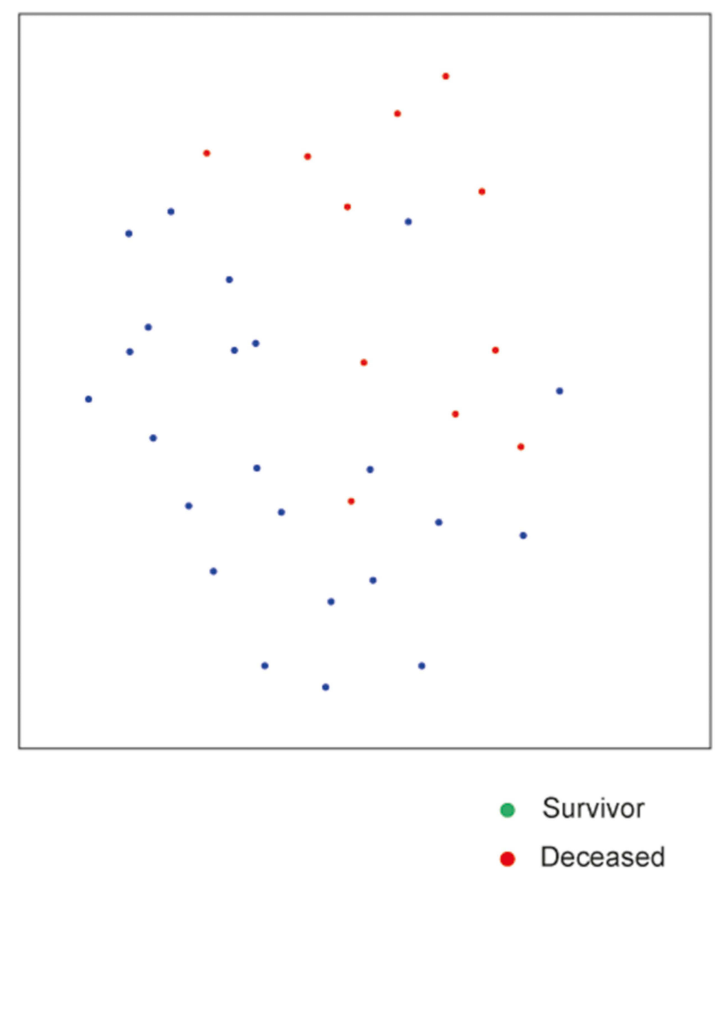

Figure 3 Biomarkers patterns are associated with mortality risk. (A) Serum markers with significantly altered serum concentration in patients who died during the course of disease. * Indicates $p<0.05$, ** $<0.005$ as calculated by two-sided T-test. (B) UMAP analysis showed a significant separation of these two groups. We clustered the individuals by 2 -means clustering and computed for each cluster how many individuals from the survival and non-survival group were contained in each cluster. Following this clustering we computed Fisher's Exact test on the $2 \times 2$ contingency table, validating a significant clustering $(p<0.01)$.

the application of OMICs technologies to array multiple layers of gene expression, protein and metabolome distribution. A multi-OMICs approach identified patterns that separate mild from severe disease. ${ }^{9}$ The combination of transcriptomics, proteomics and metabolomics revealed 219 molecular features related to COVID-19 and linked to complement activation, dysregulated lipid metabolism, and neutrophil activation. ${ }^{4}$ A dysregulation of the myeloid cell compartment was found by transcriptomics and single-cell-analysis. ${ }^{2}$

The other approach focuses on the measurement of selected biomarkers in clinically relevant cohorts. This approach does not allow a deeper insight into mechanisms but aids to quickly develop clinically relevant information. IL-1RA, IL-10, and RANTES were found to associate with disease severity in a longitudinal investigation. ${ }^{21}$ IFN- $\gamma$ and type I IFN production were found to be relatively deceased, while TNF- $\alpha$, IL-6, and IL-8 were increased for a prolonged time. ${ }^{22}$ The serial analysis of several cytokines in 113 patients showed the early rise in markers to be associated with worse outcome and an activation of type 2 cytokines in severe COVID-19. ${ }^{3}$ Measurement of IL-6, IL-8, TNF- $\alpha$, and IL-1 $\beta$ were found to be predictive for severity and survival. ${ }^{8}$ The measurement of a selected cytokine panel showed that COVID-19 is distinct from conventional pneumonia. ${ }^{7}$

The present work applied a large panel of biomarkers to COVID-19 patients and control groups. The marker panel applied in the present study consists of mediators of inflammation and immunity, most of which are not yet part of clinical routine testing but have been shown to partake in cellular or humoral immune responses. The present study confirmed several of these findings and in addition shows a more comprehensive illustration of COVID-19 systemic inflammation. The blood marker profile of COVID-19 patients differs significantly from control patients with elective non-pulmonary surgery or severe pneumonia. The data show that COVID-19 is associated with a broad and complex activation of innate and adaptive immune responses. 
In addition to several studies, ${ }^{10,23}$ the present data showed increased serum concentrations of NSE, AAT, ENRAGE, IL-18, MCP-1, PAI-1, SAP, IL-18bp, and MMP-9 in the COVID-19 cohort compared to the lung-healthy hospitalized control group. We could confirm increased levels of PAI-1 in COIVD-19 patient-samples that indicates the involvement of the plasminogen-plasmin system, however, we saw no prognostic correlation of PAI-1 concentrations with disease severity. ${ }^{15}$ Several newly identified blood markers were increased in patients with severe disease (AAT, EN-RAGE, myoglobin, SAP, TIMP-1, vWF, decorin) in addition to analytes, that had already been described (CRP, IL1-ra, IL-8, IL-10, IL-18, MCP-1). ${ }^{8,11,24}$

Published multi-omics analysis and our own observations indicate the involvement of diverse factors, that determine the final outcome of COVID-19. Therefore, we propose the use of a pattern of distinct cytokine markers, that can be easily determined by standard laboratory methods to predict the course of COVID-19. Elevated concentrations of IL-1ra, IL-8, IL-10, MCP-1, SCF, and CA-9 resulted in a $92.9 \%$ correct classification of cases in our cohort that died during the progression of COVID-19. While IL-8, and MCP-1 have already been used to predict disease severity and survival, ${ }^{8,11,12,25,26}$ the combination with new markers like SCF and CA-9 is a novel finding of this work. Elevated MCP-1 concentrations are linked with IL-6 induced elevation of PAI-1 and endothelial dysfunction, that has been shown to be a major driver for disease severity in COVID-19. ${ }^{27}$

The term "cytokine storm" in general describes the finding of an exaggerated immune response with excessively elevated cytokine levels and deleterious side effects $^{6}$ and it was often highlighted that this phenomenon would be a hallmark of COVID-19. Other reports questioned the role of a cytokine storm in COVID-19 in comparison to other inflammatory conditions. ${ }^{5}$ Also, the present results support this view with COVID-19 patients having a distinct pattern of increased inflammatory mediators but not an out-of-proportion increase.

The present study has limitations and strengths: The use of established, rapid multiplex assays allows to translate these findings to validation studies and clinical practice. One important aspect is the direct comparison to nonCOVID-19 pneumonia and a control group. The present study has included relatively few COVID-patients and does not cover very mild or asymptomatic individuals nor sequential sampling. Overfitting might be a result of low patient numbers and validation in other cohorts is mandatory.

In conclusion, COVID-19 shows a distinct inflammatory blood marker profile separate from conventional pneumonia and extrapulmonary disease. Several markers were associated with disease severity and lethal outcome. We recommend a thorough investigation which of these biomarkers might be causative for immune dysregulation in severe COVID-19 or just a by-product of immune activation. Ideally, proteins strongly connected to COVID-19 pathophysiology could reveal potential targets for immunomodulating therapies for patients at risk.

\section{Acknowledgments}

This work was supported by grants of the Rolf M. Schwiete Stiftung (2020-013), the Saarland University, and the State of Saarland. Protein biomarker assays have been performed in collaboration with Myriad RBM.

\section{Author Contributions}

All authors made a significant contribution to the work reported, whether that is in the conception, study design, execution, acquisition of data, analysis and interpretation, or in all these areas; took part in drafting, revising or critically reviewing the article; gave final approval of the version to be published; have agreed on the journal to which the article has been submitted; and agree to be accountable for all aspects of the work.

\section{Funding}

No role of the funding source.

\section{Disclosure}

Prof Dr Thomas Volk reports grants from BBraun, grants from Sedana medical, outside the submitted work. Prof Dr Robert Bals reports grants from Myriad, grants from State of Saarland, grants from Schwiete Stiftung, during the conduct of the study; grants, personal fees from various, outside the submitted work. The authors report no other conflicts of interest in this work.

\section{References}

1. Coronaviridae Study Group of the International Committee on Taxonomy of V. The species severe acute respiratory syndrome-related coronavirus: classifying $2019-\mathrm{nCoV}$ and naming it SARS-CoV-2. Nat Microbiol. 2020;5(4):536-544. doi:10.1038/s41 564-020-0695-Z 
2. Schulte-Schrepping J, Reusch N, Paclik D, et al. Severe COVID-19 is marked by a dysregulated myeloid cell compartment. Cell. 2020;182 (6):1419-1440 e1423. doi:10.1016/j.cell.2020.08.001

3. Lucas C, Wong P, Klein J, et al. Longitudinal analyses reveal immunological misfiring in severe COVID-19. Nature. 2020;584(7821): 463-469. doi:10.1038/s41586-020-2588-y

4. Overmyer KA, Shishkova E, Miller IJ, et al. Large-scale multi-omic analysis of COVID-19 severity. Cell Syst. 2020;12(1):23-40.

5. Leisman DE, Ronner L, Pinotti R, et al. Cytokine elevation in severe and critical COVID-19: a rapid systematic review, meta-analysis, and comparison with other inflammatory syndromes. Lancet Respir Med. 2020;8(12):1233-1244. doi:10.1016/S2213-2600(20)30404-5

6. Fajgenbaum DC, June CH. Cytokine Storm. N Engl J Med. 2020;383 (23):2255-2273. doi:10.1056/NEJMra2026131

7. McElvaney OJ, McEvoy NL, McElvaney OF, et al. Characterization of the inflammatory response to severe COVID-19 illness. Am $J$ Respir Crit Care Med. 2020;202(6):812-821. doi:10.1164/rccm.20 2005-15830C

8. Del Valle DM, Kim-Schulze S, Huang HH, et al. An inflammatory cytokine signature predicts COVID-19 severity and survival. Nat Med. 2020;26(10):1636-1643. doi:10.1038/s41591-020-1051-9

9. Su Y, Chen D, Yuan D. Multi-omics resolves a sharp disease-state shift between mild and moderate COVID-19. Cell. 2020;183 (6):1479-1495e1420. doi:10.1016/j.cell.2020.10.037

10. Wang J, Jiang M, Chen X, Montaner LJ. Cytokine storm and leukocyte changes in mild versus severe SARS-CoV-2 infection: review of 3939 COVID-19 patients in China and emerging pathogenesis and therapy concepts. J Leukoc Biol. 2020;108(1):17-41. doi:10.1002/ JLB.3COVR0520-272R

11. Li L, Li J, Gao M, et al. Interleukin-8 as a biomarker for disease prognosis of coronavirus disease-2019 patients. Front Immunol. 2020;11:602395. doi:10.3389/fimmu.2020.602395

12. Ma A, Zhang L, Ye X, et al. High levels of circulating IL-8 and soluble IL-2R are associated with prolonged illness in patients with severe COVID-19. Front Immunol. 2021;12:626235. doi:10.3389/ fimmu.2021.626235

13. Edler C, Schröder AS, Aepfelbacher M, et al. Dying with SARS-CoV-2 infection-an autopsy study of the first consecutive 80 cases in Hamburg, Germany. Int J Legal Med. 2020;134 (4):1275-1284. doi:10.1007/s00414-020-02317-w

14. Xu Z, Shi L, Wang Y, et al. Pathological findings of COVID-19 associated with acute respiratory distress syndrome. Lancet Respir Med. 2020;8(4):420-422. doi:10.1016/S2213-2600(20)30076-X

15. Zuo Y, Warnock M, Harbaugh A, et al. Plasma tissue plasminogen activator and plasminogen activator inhibitor-1 in hospitalized COVID-19 patients. Sci Rep. 2021;11(1):1580. doi:10.1038/s41598$020-80010-z$
16. Hammer S, Häberle H, Schlensak C, et al. Severe SARS-CoV-2 infection inhibits fibrinolysis leading to changes in viscoelastic properties of blood clot: a Descriptive Study of fibrinolysis in COVID-19. Thromb Haemost. 2021. doi:10.1055/a-1400-6034

17. Della-Morte D, Pacifici F, Ricordi C, et al. Low level of plasminogen increases risk for mortality in COVID-19 patients. Cell Death Dis. 2021;12(8):773. doi:10.1038/s41419-021-04070-3

18. Lepper PM, Ott S, Nuesch E, et al. German community acquired pneumonia competence N. serum glucose levels for predicting death in patients admitted to hospital for community acquired pneumonia: prospective cohort study. BMJ. 2012;344(may28 4):e3397. doi:10.11 36/bmj.e3397

19. Kruger S, Papassotiriou J, Marre R, et al. Pro-atrial natriuretic peptide and pro-vasopressin to predict severity and prognosis in community-acquired pneumonia: results from the German competence network CAPNETZ. Intensive Care Med. 2007;33(12):20 69-2078. doi:10.1007/s00134-007-0895-5

20. Christ-Crain M, Stolz D, Bingisser R, et al. Procalcitonin guidance of antibiotic therapy in community-acquired pneumonia: a randomized trial. Am J Respir Crit Care Med. 2006;174(1):84-93. doi:10.1164/ rccm.200512-1922OC

21. Zhao Y, Qin L, Zhang P, et al. Longitudinal COVID-19 profiling associates IL-1RA and IL-10 with disease severity and RANTES with mild disease. JCI Insight. 2020;5(13):13. doi:10.1172/jci. insight. 139834

22. Galani IE, Rovina N, Lampropoulou V, et al. Untuned antiviral immunity in COVID-19 revealed by temporal type I/III interferon patterns and flu comparison. Nat Immunol. 2021;22(1):32-40. doi:10.1038/s41590-020-00840-X

23. Hu B, Huang S, Yin L. The cytokine storm and COVID-19. J Med Virol. 2021;93(1):250-256. doi:10.1002/jmv.26232

24. Sindelar M, Stancliffe E, Schwaiger-Haber M, et al. Longitudinal metabolomics of human plasma reveals prognostic markers of COVID-19 disease severity. Cell Rep Med. 2021;2(8):100369. doi:10.1016/j.xcrm.2021.100369

25. Chen Y, Wang J, Liu C, et al. IP-10 and MCP-1 as biomarkers associated with disease severity of COVID-19. Mol Med. 2020;26 (1):97. doi:10.1186/s10020-020-00230-X

26. Li H, Zhang J, Fang C, et al. The prognostic value of IL- 8 for the death of severe or critical patients with COVID-19. Medicine (Baltimore). 2021;100(11):e23656. doi:10.1097/MD.0000000000023656

27. Kang S, Tanaka T, Inoue H, et al. IL-6 trans-signaling induces plasminogen activator inhibitor-1 from vascular endothelial cells in cytokine release syndrome. Proc Natl Acad Sci U S A. 2020;117 (36):22351-22356. doi:10.1073/pnas.2010229117
Journal of Inflammation Research

\section{Publish your work in this journal}

The Journal of Inflammation Research is an international, peerreviewed open-access journal that welcomes laboratory and clinica findings on the molecular basis, cell biology and pharmacology of inflammation including original research, reviews, symposium reports, hypothesis formation and commentaries on: acute/chronic inflammation; mediators of inflammation; cellular processes; molecular mechanisms; pharmacology and novel anti-inflammatory drugs; clinical conditions involving inflammation. The manuscript management system is completely online and includes a very quick and fair peerreview system. Visit http://www.dovepress.com/testimonials.php to read real quotes from published authors. 